\title{
Platelet-to-lymphocyte ratio is an independent prognosticator in patients with esophageal squamous cell carcinoma receiving esophagectomy
}

\author{
Li-Chun Chen ${ }^{1}$, Shau-Hsuan $\mathrm{Li}^{2}$, Chien-Ming Lo ${ }^{1}$, Yen-Hao Chen ${ }^{2}$, Shun-Chen Huang ${ }^{3}$, \\ Yu-Ming Wang ${ }^{4}$, Shang-Yu Chou ${ }^{4}$, Hung-I Lu ${ }^{1}$ \\ ${ }^{1}$ Department of Thoracic \& Cardiovascular Surgery, ${ }^{2}$ Department of Hematology-Oncology, ${ }^{3}$ Department of Pathology, ${ }^{4}$ Department of Radiation \\ Oncology, Kaohsiung Chang Gung Memorial Hospital and Chang Gung University College of Medicine, Kaohsiung \\ Contributions: (I) Conception and design: LC Chen, HI Lu; (II) Administrative support: SH Li, HI Lu; (III) Provision of study materials or patients: \\ SH Li, HI Lu, CM Lo, YH Chen, SC Huang, YM Wang, SY Chou; (IV) Collection and assembly of data: LC Chen, SH Li; (V) Data analysis and \\ interpretation: LC Chen, SH Li, HI Lu; (VI) Manuscript writing: All authors; (VII) Final approval of manuscript: All authors. \\ Correspondence to: Hung-I Lu, MD. Department of Thoracic \& Cardiovascular Surgery, Kaohsiung Chang Gung Memorial Hospital and Chang \\ Gung University College of Medicine, No. 123, Dapi Rd., Niaosong Dist., Kaohsiung City 833. Email: luhungi@yahoo.com.tw.
}

Background: Systemic inflammation response is a crucial prognostic factor for various cancers. The neutrophil-to-lymphocyte ratio (NLR) and platelet-to-lymphocyte ratio (PLR) are two inflammation-based prognostic scores. The significance of preoperative NLR and PLR in patients with esophageal squamous cell carcinoma (ESCC) receiving curative esophagectomy remains largely undefined. Hence, this study aimed to evaluate the significance of preoperative NLR and PLR in patients with ESCC receiving curative esophagectomy in southern Taiwan.

Methods: A consecutive group of 107 patients with ESCC undergoing esophagectomy between January 2001 and December 2012 were retrospectively reviewed. The NLR and PLR of these 107 patients were calculated and correlated with clinicopathological parameters, overall survival (OS), and disease-free survival (DFS).

Results: NLR $\geq 2.5$ was significantly correlated with higher $T$ classification $(\mathrm{P}=0.006)$ and advanced clinical AJCC $7^{\text {th }}$ stage $(\mathrm{P}=0.047)$. PLR $\geq 150$ was significantly associated with higher $\mathrm{T}$ classification $(\mathrm{P}=0.009)$. Univariate survival analysis showed that $\mathrm{NLR} \geq 2.5$ and $\mathrm{PLR} \geq 150$ were associated with poor $\mathrm{OS}(\mathrm{P}=0.009$ and $\mathrm{P}=0.007$, respectively) and poor DFS ( $\mathrm{P}=0.006$ and $\mathrm{P}=0.005$, respectively). On multivariate comparison, $\mathrm{PLR} \geq 150$ was independently associated with poor OS [P=0.001, hazard ratio (HR): 2.475] and poor DFS $(\mathrm{P}<0.001$, HR: 2.509). The 5-year overall and DFS rates were, respectively, $33.3 \%$ and $25.0 \%$ in patients with PLR $\geq 150$, and $54 \%$ and $46 \%$ in patients with PLR $<150$.

Conclusions: The PLR is an independent prognosticator for patients with ESCC undergoing esophagectomy in southern Taiwan.

Keywords: Esophageal cancer; squamous cell carcinoma; neutrophil-to-lymphocyte ratio (NLR); platelet-tolymphocyte ratio (PLR); esophagectomy

Submitted Feb 18, 2019. Accepted for publication Oct 10, 2019.

doi: $10.21037 /$ jtd.2019.11.06

View this article at: http://dx.doi.org/10.21037/jtd.2019.11.06

(C) Journal of Thoracic Disease. All rights reserved. 


\section{Introduction}

Globally, esophageal cancer was the seventh most common cancer and sixth most common cause of death in 2018 (1). In Taiwan, the major histology of esophageal cancer is squamous cell carcinoma, and esophageal cancer caused approximately 1,731 deaths in 2016 . The 5 -year survival of patients with esophageal cancer ranges from $15 \%$ to $20 \%$ (2). The prognosis of patients with esophageal squamous cell carcinoma (ESCC) remains poor even though radical surgery, chemotherapy, and radiotherapy have been performed since decades (3-5). Although patients with ESCC receive radical surgery and chemoradiotherapy, recurrence occurs (5). Hence, identifying easily available prognostic markers for ESCC is crucial for clinicians to prepare appropriate risk-adapted treatment plans.

Systemic inflammation is associated with the prognosis of various cancers (6). Indicators of systemic inflammatory response, such as neutrophil-to-lymphocyte ratio (NLR) and platelet-to-lymphocyte ratio (PLR), have been investigated for their prognostic value in predicting the prognosis of various cancers $(7,8)$. However, only a few studies have investigated the prognostic value of NLR and PLR for patients with esophageal cancer. Moreover, the significance of preoperative NLR and PLR in patients with ESCC receiving curative esophagectomy in southern Taiwan remains largely undefined. Therefore, we conducted a retrospective analysis to determine the significance of NLR and PLR in patients with ESCC undergoing curative esophagectomy in southern Taiwan.

\section{Methods}

\section{Patient population}

Patients with ESCC who underwent surgical resection at Kaohsiung Chang Gung Memorial Hospital between January 2001 and December 2012 were retrospectively evaluated. This retrospective study was approved by the Chang Gung Medical Foundation Institutional Review Board (No. 201901532B0). After excluding patients treated with preoperative chemoradiotherapy, those treated with preoperative chemotherapy or radiotherapy, those with synchronous cancers, and those lost to follow-up, 107 patients receiving esophagectomy were enrolled and analyzed. Radical esophagectomy (the McKeown procedure or Ivor Lewis procedure), reconstruction with gastric tube pull-up, and two-field lymph node dissection were performed. The pathological TNM stage was determined according to the $7^{\text {th }}$ American Joint Committee on Cancer (AJCC) staging system. Follow-ups were performed every 3 months in years 1 and 2, every 6 months in years 3-5, and after 1 year thereafter. Overall survival (OS) was defined as the time of surgery to death from any cause. Diseasefree survival (DFS) was calculated from the time of surgery to recurrence or death from any cause without evidence of recurrence.

\section{NLR and PLR}

The neutrophil count, lymphocyte count, and platelet count before esophagectomy were retrospectively recorded for the included 107 patients. The NLR was defined as the neutrophil count divided by the lymphocyte count, and the PLR was calculated by dividing the platelet count by the lymphocyte count; the cut-off values for the NLR and PLR were 2.5 and 150 , respectively, according to previous studies $(9,10)$.

\section{Statistical analysis}

Comparisons between groups were performed using the chi-square test and Fisher's exact test. Survival was calculated using the Kaplan-Meier method for univariate analysis, and the differences were assessed using the longrank test. Multivariate analysis for significant parameters at the univariate level was performed using the Cox regression model in a stepwise forward fashion. Statistical significance was defined as $\mathrm{P}<0.05$. All analyses were conducted using SPSS21.0 software package (IBM Corp. Released 2012. IBM SPSS Statistics for Window, Version 21.0. Armonk, NY, USA).

\section{Results}

\section{Patient characteristics}

A total of 107 patients were enrolled (104 men and 3 women), and the median age was 55 years (range, 29-80 years). The clinicopathological characteristics are shown in Table 1.

Table 2 shows the correlations between NLR and PLR, and the clinicopathological parameters. NLR $\geq 2.5$ was significantly associated with the $\mathrm{T}$ classification $\mathrm{T} 3+\mathrm{T} 4$ $(\mathrm{P}=0.006), 7^{\text {th }}$ AJCC stage III $(\mathrm{P}=0.047)$, positive surgical margin $(\mathrm{P}=0.039)$, and $\mathrm{PLR} \geq 150(\mathrm{P}<0.001)$. $\mathrm{PLR} \geq 150$ was significantly correlated with the $\mathrm{T}$ classification $\mathrm{T} 3+\mathrm{T} 4$ $(\mathrm{P}=0.009)$. 
Table 1 The general characteristics of 107 patients with esophageal squamous cell carcinoma receiving esophagectomy

\begin{tabular}{|c|c|}
\hline Variables & $\mathrm{N}(\%)$ \\
\hline Age, years & Median: 55; mean: 56; range, 29-80 \\
\hline \multicolumn{2}{|l|}{ Sex } \\
\hline Male & $104(97.2)$ \\
\hline Female & $3(2.8)$ \\
\hline \multicolumn{2}{|c|}{ Primary tumor location } \\
\hline Upper & $20(18.7)$ \\
\hline Middle & $40(37.4)$ \\
\hline Lower & $47(43.9)$ \\
\hline \multicolumn{2}{|c|}{ T classification } \\
\hline T1 & $47(43.9)$ \\
\hline T2 & $25(23.4)$ \\
\hline T3 & $25(23.4)$ \\
\hline T4 & $10(9.3)$ \\
\hline \multicolumn{2}{|c|}{$\mathrm{N}$ classification } \\
\hline NO & $71(66.4)$ \\
\hline N1 & $24(22.4)$ \\
\hline N2 & $10(9.3)$ \\
\hline N3 & $2(1.9)$ \\
\hline \multicolumn{2}{|c|}{$7^{\text {th }}$ AJCC stage } \\
\hline IA & $5(4.7)$ \\
\hline IB & $37(34.6)$ \\
\hline$\| \mathrm{A}$ & $11(10.3)$ \\
\hline IIB & $28(26.2)$ \\
\hline IIIA & $11(10.3)$ \\
\hline IIIB & $4(3.7)$ \\
\hline IIIC & $11(10.3)$ \\
\hline \multicolumn{2}{|c|}{ Histological grading } \\
\hline Grade 1 & $11(10.3)$ \\
\hline Grade 2 & $70(65.4)$ \\
\hline Grade 3 & $26(24.3)$ \\
\hline \multicolumn{2}{|c|}{ Surgical margin } \\
\hline Negative & $96(89.7)$ \\
\hline Positive & $11(10.3)$ \\
\hline
\end{tabular}

Table 1 (continued)
Table 1 (continued)

\begin{tabular}{ll}
\hline Variables & $\mathrm{N}(\%)$ \\
\hline NLR & \\
NLR $<2.5$ & $51(47.7)$ \\
NLR $\geq 2.5$ & $56(52.3)$ \\
PLR & \\
PLR $<150$ & $59(55.1)$ \\
PLR $\geq 150$ & $48(44.9)$ \\
\hline
\end{tabular}

AJCC, American Joint Committee on Cancer; NLR, neutrophilto-lymphocyte ratio; PLR, platelet-to-lymphocyte ratio

\section{Survival analyses}

At the time of analysis, the median follow-up periods were 65 months (range, 60.4-112 months) for 52 survivors and 58 months (range, 1.3-112 months) for all 107 patients. The 5-year OS and DFS rates for these 107 patients were $49 \%$ and $40 \%$, respectively.

Table 3 shows the correlations between the clinicopathological parameters, PLR, and NLR, and the OS and DFS. Univariate survival analyses found that the T classification $\mathrm{T} 3+\mathrm{T} 4(\mathrm{P}=0.02), \mathrm{N}$ classification $\mathrm{N} 1+2+3$ $(\mathrm{P}<0.001), 7^{\text {th }}$ AJCC stage II $+\mathrm{III}(\mathrm{P}=0.011)$, positive surgical margins $(\mathrm{P}=0.004), \mathrm{NLR} \geq 2.5(\mathrm{P}=0.009)$ and $\mathrm{PLR} \geq 150$ $(\mathrm{P}=0.007)$ were significantly associated with poor $\mathrm{OS}$. The $\mathrm{T}$ classification $\mathrm{T} 3+\mathrm{T} 4(\mathrm{P}=0.004), \mathrm{N}$ classification $\mathrm{N} 1+2+3$ $(\mathrm{P}<0.001), 7^{\text {th }}$ AJCC stage $\mathrm{II}+\mathrm{III}(\mathrm{P}=0.009)$, positive surgical margins $(\mathrm{P}=0.018), \mathrm{NLR} \geq 2.5(\mathrm{P}=0.006)$, and $\mathrm{PLR} \geq 150$ $(\mathrm{P}=0.005)$ were significantly associated with poor DFS.

The 5 -year OS rates were $54.9 \%$ and $35.7 \%$ in patients with NLR $<2.5$ and NLR $\geq 2.5$, respectively ( $\mathrm{P}=0.009$; Figure $1 A$ ), and the 5 -year DFS rates were $47.1 \%$ and $26.8 \%$ $(\mathrm{P}=0.006$; Figure $1 \mathrm{~B})$. The 5 -year OS rate were $54.2 \%$ and $33.3 \%$ in patients with PLR $<150$ and PLR $\geq 150$, respectively $(\mathrm{P}=0.007$; Figure $1 C)$ and the 5 -year DFS rates were $45.8 \%$ and $25.0 \%(\mathrm{P}=0.005$; Figure $1 D)$. Table 4 shows the results of multivariate analysis. PLR $\geq 150$ and lymph node classification $\mathrm{N} 1+2+3$ were significantly independently associated with poor $\mathrm{OS}[\mathrm{P}=0.001$, hazard ratio $(\mathrm{HR}): 2.475$; 95\% confidence interval (CI), 1.458-4.023; $\mathrm{P}<0.001$, HR: 3.893; 95\% CI, 2.268-6.683]. Additionally, independent factors for poor DFS were PLR $\geq 150(\mathrm{P}<0.001$, HR: 2.509; 95\% CI, 1.523-4.135) and lymph node classification 
Table 2 Associations between NLR and PLR and the clinicopathological parameters in 107 patients with esophageal squamous cell carcinoma receiving esophagectomy

\begin{tabular}{|c|c|c|c|c|c|c|}
\hline Parameters & \multicolumn{3}{|c|}{ NLR } & \multicolumn{3}{|c|}{ PLR } \\
\hline \multicolumn{7}{|l|}{ Age, years } \\
\hline$<55$ & 19 & 34 & $0.015^{\star}$ & 27 & 26 & 0.387 \\
\hline$\geq 55$ & 32 & 22 & & 32 & 22 & \\
\hline \multicolumn{7}{|c|}{ Primary tumor location } \\
\hline $\mathrm{U}+\mathrm{M}$ & 29 & 31 & 0.875 & 34 & 26 & 0.720 \\
\hline L & 22 & 25 & & 25 & 22 & \\
\hline \multicolumn{7}{|c|}{$\mathrm{T}$ classification } \\
\hline $\mathrm{T} 1+\mathrm{T} 2$ & 41 & 31 & $0.006^{*}$ & 46 & 26 & $0.009^{*}$ \\
\hline No & 35 & 36 & 0.635 & 39 & 32 & 0.951 \\
\hline $\mathrm{N} 1+2+3$ & 16 & 20 & & 20 & 16 & \\
\hline \multicolumn{7}{|c|}{$7^{\text {th }}$ AJCC stage } \\
\hline I & 22 & 20 & 0.432 & 24 & 18 & 0.738 \\
\hline II+III & 29 & 36 & & 35 & 30 & \\
\hline \multicolumn{7}{|c|}{$7^{\text {th }}$ AJCC stage } \\
\hline $\mathrm{I}+\mathrm{II}$ & 43 & 38 & $0.047^{\star}$ & 47 & 34 & 0.290 \\
\hline III & 8 & 18 & & 12 & 14 & \\
\hline Positive & 2 & 9 & & 3 & 8 & \\
\hline \multicolumn{7}{|l|}{ PLR } \\
\hline$<150$ & 49 & 10 & $<0.001^{*}$ & - & - & - \\
\hline$\geq 150$ & 2 & 46 & & - & - & - \\
\hline
\end{tabular}
${ }^{*}$, statistically significant. AJCC, American Joint Committee on Cancer; NLR, neutrophil-to-lymphocyte ratio; PLR, platelet-to-lymphocyte ratio.

$\mathrm{N} 1+2+3,(\mathrm{P}<0.001, \mathrm{HR}: 3.372 ; 95 \% \mathrm{CI}, 2.014-5.646)$.

\section{Discussion}

Abundant evidence shows that systemic inflammation response is associated with tumor proliferation and progression $(11,12)$ as well as cancer prognosis $(7,8,10)$. Neutrophilia and thrombocytosis are caused by inflammatory responses resulting from cancer (13). Megakaryocytes are motivated by pro-inflammatory 
Table 3 Results of univariate log-rank analysis of prognostic factors for overall survival and disease-free survival in 107 patients with esophageal squamous cell carcinoma receiving esophagectomy

\begin{tabular}{|c|c|c|c|c|c|}
\hline Factors & No. of patients & \multicolumn{2}{|c|}{ Overall survival (OS) } & \multicolumn{2}{|c|}{ Disease-free survival (DFS) } \\
\hline \multicolumn{6}{|l|}{ Age, years } \\
\hline$<55$ & 53 & 50.9 & 0.298 & 45.3 & 0.105 \\
\hline$\geq 55$ & 54 & 38.9 & & 27.8 & \\
\hline $\mathrm{U}+\mathrm{M}$ & 60 & 50 & 0.196 & 38.3 & 0.373 \\
\hline L & 47 & 38.3 & & 34 & \\
\hline \multicolumn{6}{|c|}{ T classification } \\
\hline $\mathrm{T} 1+2$ & 72 & 52.8 & $0.02^{*}$ & 41.3 & $0.004^{*}$ \\
\hline \multicolumn{6}{|c|}{$\mathrm{N}$ classification } \\
\hline NO & 71 & 56.3 & $<0.001^{\star}$ & 45.1 & $<0.001^{\star}$ \\
\hline $\mathrm{N} 1+2+3$ & 36 & 22.2 & & 19.4 & \\
\hline \multicolumn{6}{|c|}{$7^{\text {th }}$ AJCC stage } \\
\hline I & 42 & 57.1 & $0.011^{*}$ & 49.6 & $0.009^{*}$ \\
\hline$\|+I I I$ & 65 & 36.9 & & 29.2 & \\
\hline \multicolumn{6}{|c|}{$7^{\text {th }}$ AJCC stage } \\
\hline $1+I I$ & 81 & 53.1 & $<0.001^{*}$ & 42.0 & $<0.001^{*}$ \\
\hline III & 26 & 19.2 & & 19.2 & \\
\hline Positive & 11 & 18.2 & & 18.2 & \\
\hline \multicolumn{6}{|l|}{ NLR } \\
\hline$<2.5$ & 51 & 54.9 & $0.009^{*}$ & 47.1 & $0.006^{*}$ \\
\hline$\geq 2.5$ & 56 & 35.7 & & 26.8 & \\
\hline \multicolumn{6}{|l|}{ PLR } \\
\hline$<150$ & 59 & 54.2 & $0.007^{\star}$ & 45.8 & $0.005^{\star}$ \\
\hline$\geq 150$ & 48 & 33.3 & & 25.0 & \\
\hline
\end{tabular}

*, statistically significant. AJCC, American Joint Committee on Cancer; NLR, neutrophil-to-lymphocyte ratio; PLR, platelet-to-lymphocyte ratio. 

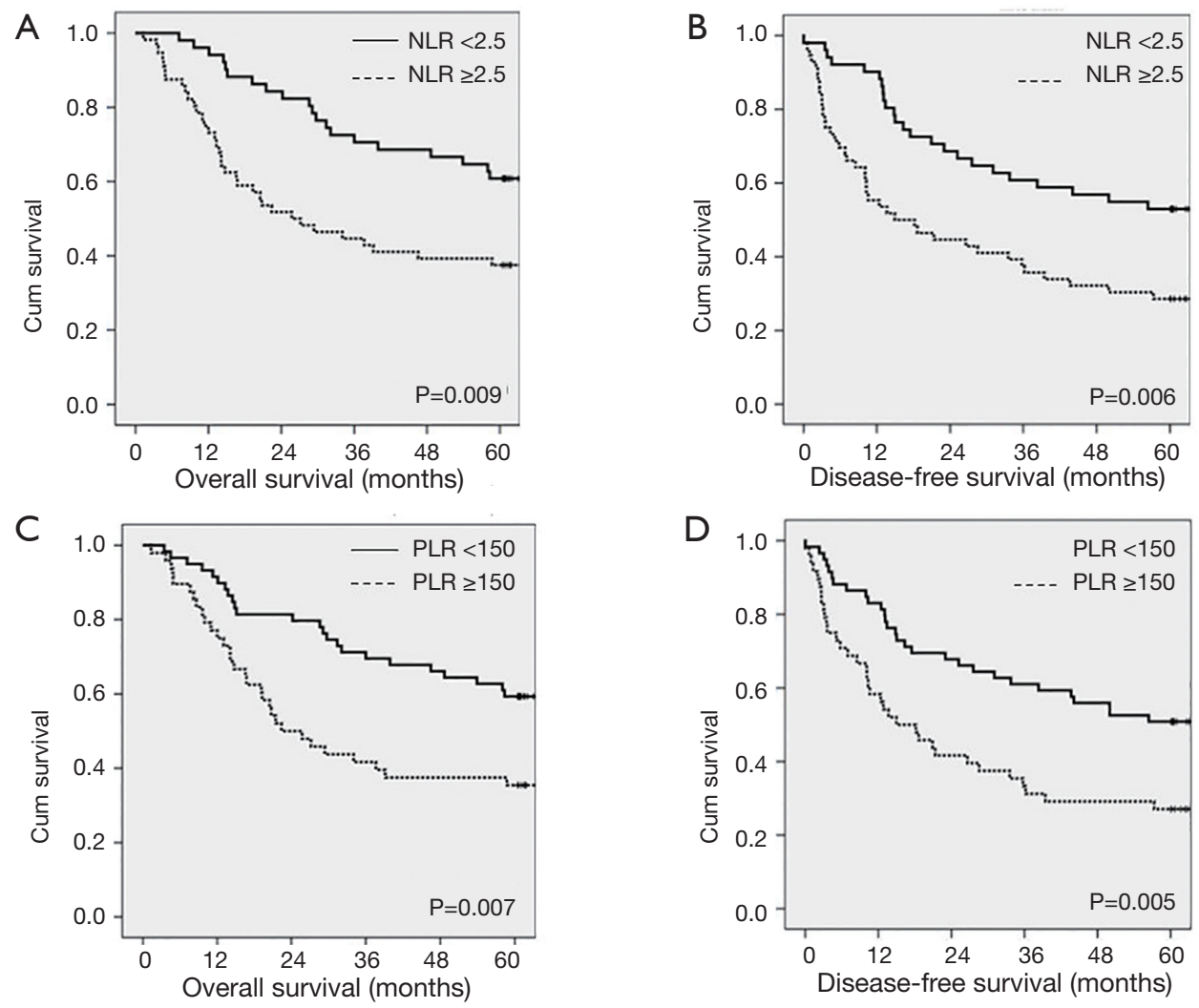

Figure 1 Kaplan-Meier curves according to the neutrophil-to-lymphocyte ratio (NLR) and platelet-to-lymphocyte ratio (PLR). (A) Overall survival curve according to the NLR; (B) disease-free survival curve according to the NLR; (C) overall survival curve according to the PLR; (D) disease-free survival curve according to the PLR.

Table 4 Results of multivariate Cox regression analysis for overall survival and disease-free survival in 107 patients with esophageal squamous cell carcinoma receiving esophagectomy

\begin{tabular}{lcccc}
\hline \multirow{2}{*}{ Factors } & \multicolumn{2}{c}{ Overall survival } & & \multicolumn{2}{c}{ Disease-free survival } \\
\cline { 2 - 4 } & OR $(95 \% \mathrm{Cl})$ & P value & OR $(95 \% \mathrm{Cl})$ & $\mathrm{P}$ value \\
\hline Platelet lymphocyte ratio: PLR $\geq 150$ & $2.475(1.458-4.203)$ & $0.001^{*}$ & $2.509(1.523-4.135)$ & $<0.001^{*}$ \\
N classification: N1+2+3 & $3.893(2.268-6.683)$ & $<0.001^{*}$ & $3.372(2.014-5.646)$ & $<0.001^{*}$ \\
\hline
\end{tabular}

*, statistically significant. OR, odds ratio; $95 \% \mathrm{Cl}, 95 \%$ confidence interval.

mediators such as interleukin (IL)-1, IL-2, and IL-6 caused by inflammation that results in a higher platelet count (9). NLR and PLR have been found to be prognostic factors in colorectal, gastric, lung, and ovarian cancers (14). However, whether preoperative PLR is a significant prognosticator in ESCC remains controversial. In previous studies, preoperative PLR was not an independent prognosticator for patients with esophageal cancer undergoing esophagectomy (15-18). In contrast, Xie et al. (19), Feng et al. (9), and Zhao et al. (6) demonstrated that preoperative PLR was an independent prognostic factor. These differences in results may be owing to the differences in the cut-off values of PLR, histology, treatment methods, and the definition of outcomes.

In our study, the cut-off value of NLR and PLR was 2.5 and 150 , respectively. Both NLR $\geq 2.5$ and PLR $\geq 150$ were correlated with poor OS and DFS in 107 patients with ESCC receiving curative esophagectomy. However, 
on multivariate analysis, only preoperative PLR was a significantly prognosticator.

Esophagectomy is one of the standard therapies for patients with ESCC, especially for patient with early stage disease. Extensive improvement in surgical techniques and perioperative monitoring has been achieved during the past decades. However, despite radical surgery, patients still develop recurrence and metastases, and the treatment outcomes were poor. Many studies (20,21) evaluating postoperative adjuvant therapy were performed to improve the inadequate survival rate achieved with esophagectomy alone. Therefore, it is important to recognize high-risk patients with tumor recurrence who may benefit from postoperative adjuvant therapy. In the present study, elevated PLR and NLR were highly representative of tumor aggressiveness and associated with poor DFS. The 5-year DFS rates were $26.8 \%$ and $47.1 \%$ in patients with NLR $\geq 2.5$ and NLR $<2.5$, respectively. The 5-year DFS rates were $25 \%$ and $45.8 \%$ in patients with PLR $\geq 150$ and PLR $<150$, respectively. These results indicate that elevated NLR and PLR may be helpful in the selection of some patients for post-operative adjuvant therapy. Furthermore, the PLR and NLR are easily measurable and available, and both are often regarded as routine preoperative tests in clinical practice.

This study has some limitations. The enrolled patient number was small and all the patients were from a single institution. Moreover, the study was retrospective, and may have had selection bias.

In conclusion, the results of our study suggest that PLR is an independent prognosticator for patients with ESCC undergoing esophagectomy and may be helpful in clinical practice.

\section{Acknowledgments}

None.

\section{Footnote}

Conflicts of Interest: The authors have no conflicts of interest to declare.

Ethical Statement: The authors are accountable for all aspects of the work in ensuring that questions related to the accuracy or integrity of any part of the work are appropriately investigated and resolved. This retrospective study was approved by the Chang Gung Medical Foundation Institutional Review Board
(No. 201901532B0).

\section{References}

1. Bray F, Ferlay J, Soerjomataram I, et al. Global cancer statistics 2018: GLOBOCAN estimates of incidence and mortality worldwide for 36 cancers in 185 countries. CA Cancer J Clin 2018;68:394-424.

2. Hyder J, Boggs DH, Hanna A, et al. Changes in neutrophil-to-lymphocyte and platelet-to-lymphocyte ratios during chemoradiation predict for survival and pathologic complete response in trimodality esophageal cancer patients. J Gastrointest Oncol 2016;7:189-95.

3. Liu J, Xie X, Zhou C, et al. Which factors are associated with actual 5 -year survival of oesophageal squamous cell carcinoma? Eur J Cardiothorac Surg 2012;41:e7-11.

4. Li SH, Lu HI, Chang AY, et al. Angiotensin II type I receptor (AT1R) is an independent prognosticator of esophageal squamous cell carcinoma and promotes cells proliferation via mTOR activation. Oncotarget 2016;7:67150-65.

5. Li SH, Chen CH, Lu HI, et al. Phosphorylated p70S6K expression is an independent prognosticator for patients with esophageal squamous cell carcinoma. Surgery 2015;157:570-80.

6. Zhao QT, Zhang XP, Zhang H, et al. Prognostic role of platelet to lymphocyte ratio in esophageal cancer: A metaanalysis. Oncotarget 2017;8:112085-93.

7. Song W, Wang K, Zhong FP, et al. Clinicopathological and prognostic significance of platelet-to-lymphocyte ratio in patients with hepatocellular carcinoma. Oncotarget 2016;7:81830-8.

8. Proctor MJ, Morrison DS, Talwar D, et al. A comparison of inflammation-based prognostic scores in patients with cancer. A Glasgow Inflammation Outcome Study. Eur J Cancer 2011;47:2633-41.

9. Feng JF, Huang Y, Chen QX. Preoperative platelet lymphocyte ratio (PLR) is superior to neutrophil lymphocyte ratio (NLR) as a predictive factor in patients with esophageal squamous cell carcinoma. World J Surg Oncol 2014;12:58.

10. Yodying H, Matsuda A, Miyashita M, et al. Prognostic Significance of Neutrophil-to-Lymphocyte Ratio and Platelet-to-Lymphocyte Ratio in Oncologic Outcomes of Esophageal Cancer: A Systematic Review and Metaanalysis. Ann Surg Oncol 2016;23:646-54.

11. Balkwill F, Mantovani A. Inflammation and cancer: back to Virchow? Lancet 2001;357:539-45. 
12. Mantovani A, Allavena P, Sica A, et al. Cancer-related inflammation. Nature 2008;454:436-44.

13. Dutta S, Crumley AB, Fullarton GM, et al. Comparison of the prognostic value of tumour- and patient-related factors in patients undergoing potentially curative resection of oesophageal cancer. World J Surg 2011;35:1861-6.

14. Asher V, Lee J, Innamaa A, et al. Preoperative platelet lymphocyte ratio as an independent prognostic marker in ovarian cancer. Clin Transl Oncol 2011;13:499-503.

15. Hirahara N, Matsubara T, Mizota Y, et al. Prognostic value of preoperative inflammatory response biomarkers in patients with esophageal cancer who undergo a curative thoracoscopic esophagectomy. BMC Surg 2016;16:66.

16. Toyokawa T, Kubo N, Tamura T, et al. The pretreatment Controlling Nutritional Status (CONUT) score is an independent prognostic factor in patients with resectable thoracic esophageal squamous cell carcinoma: results from a retrospective study. BMC Cancer 2016;16:722.

17. Zhang F, Chen Z, Wang P, et al. Combination of platelet count and mean platelet volume (COP-MPV) predicts

Cite this article as: Chen LC, Li SH, Lo CM, Chen YH, Huang SC, Wang YM, Chou SY, Lu HI. Plateletto-lymphocyte ratio is an independent prognosticator in patients with esophageal squamous cell carcinoma receiving esophagectomy. J Thorac Dis 2019;11(11):4583-4590. doi: 10.21037/jtd.2019.11.06 postoperative prognosis in both resectable early and advanced stage esophageal squamous cell cancer patients. Tumour Biol 2016;37:9323-31.

18. Han LH, Jia YB, Song QX, et al. Prognostic significance of preoperative lymphocyte-monocyte ratio in patients with resectable esophageal squamous cell carcinoma. Asian Pac J Cancer Prev 2015;16:2245-50.

19. Xie X, Luo KJ, Hu Y, et al. Prognostic value of preoperative platelet-lymphocyte and neutrophillymphocyte ratio in patients undergoing surgery for esophageal squamous cell cancer. Dis Esophagus 2016;29:79-85.

20. Barnett SA, Rizk NP. Randomized clinical trials in esophageal carcinoma. Surg Oncol Clin N Am 2010;19:59-80.

21. Chiu TJ, Lu HI, Chen CH, et al. Osteopontin Expression Is Associated with the Poor Prognosis in Patients with Locally Advanced Esophageal Squamous Cell Carcinoma Receiving Preoperative Chemoradiotherapy. Biomed Res Int 2018;2018:9098215. 